\title{
Correction to: Imaging and Genetic Approaches to Inform Biomarkers for Anxiety Disorders, Obsessive-Compulsive Disorders, and PSTD
}

Eduard Maron, Chen-Chia Lan, and David Nutt

Correction to:

Chapter "Imaging and Genetic Approaches to Inform

Biomarkers for Anxiety Disorders, Obsessive-Compulsive

Disorders, and PSTD" in: E. Maron et al.,

Curr Topics Behav Neurosci,

DOI 10.1007/7854_2018_49

This chapter was inadvertently published with Fig. 1 which do not belong to this chapter and hence Fig. 1 is deleted from this chapter later.

The updated online version of this chapter can be found at DOI 10.1007/7854_2018_49 